\title{
Entry and Exit Strategies in Migration Dynamics
}

\author{
Sergio Vergalli*
}

March 1, 2009

\begin{abstract}
This work is devoted to study the role of combined entry and exit strategies in the migration process. It develops a real option model in which the community of immigrants in the host country is described as a club and the immigrant's benefits is an inverse U-shaped function, depending on the dimension of the district. There exist two threshold levels: the first one triggers the migration choice, while the second triggers the return to the country of origin. The theoretical results show that the phenomenon of hysteresis is amplified by the existence of a community both in the entry case and in the exit case. Furthermore, the community can reduce the minimum wage level required to trigger both exit and entry: this fact could explain why in some cases we observe migration inflows with a low wage differential and also with underemployment. Finally, the paper shows some possible further extensions: in one case, by introducing heterogeneity among immigrants, it gives some intuitions about migration inflows with respect to different skill levels and, in another case, it shows some theoretical implementations to include policy shocks in the migrant's choice.
\end{abstract}

JEL Classification Numbers: F22, H49, O15, R23.

Keywords: Migration, Real Option, Theory of Clubs, Network Effect.

\footnotetext{
*University of Brescia, Department of Economics, via S.Faustino 74/b, Brescia, Italy, ver-
} galli@eco.unibs.it. 


\section{Introduction}

So far, theoretical approaches that use real option framework to study migration choice, assume that migration is an irreversible choice. Nevertheless, economic literature show that migration could be thought also as a temporary phenomenon (Hill, 1987; Djajic, 1989; Dustmann, 2001; Dustmann and Weiss, 2007). Therefore real option approach could be extended by taking into account that migration could be thought as the combined effect of entry and exit strategies. By following this idea, this work is devoted to include combined entry and exit strategies in recent real option literature applied to migration study. Moreover, in this framework, the paper studies how the community of immigrants, described as a club, is able to affect migration net waves in the host country. What happens in the labour market? What does it change in the migration choice?

Many works in economic literature view migration as permanent ${ }^{1}$. The fact that the migration decision is in many cases at least partially irreversible, added to uncertainty over the wage differentials and the economic conditions in the host country ${ }^{2}$, that push the postponable migration choice, is an important element that enabled Burda (1995) to adapt the real option approach to migration decision assumed, in line with Sjaastad (1962), as an investment decision. Burda's results show that individuals prefer to wait before migrating, even if the present value of the wage differential is positive, because of the uncertainty and the sunk costs associated with migration ${ }^{3}$. Therefore the novelty introduced by the real option approach consists in studying the dynamic choice of a representative agent, taking into account the value of postponable choice, that is the value of waiting. Subsequently Khwaja (2002), Anam et al. (2007), Moretto and Vergalli (2008), developed Burda's approach by describing the role of uncertainty in the migration decision. Another work that uses real option with respect to an argument that it is strictly related to migration is Feist's (1998) paper, in which the author analyses the option value of the low-skilled workers to escape to the unofficial sector if welfare benefits come too close to the net wage in the official sector. In a recent work, Vergalli (2008) studies migration choice by merging in a unified framework the real option approach of investment decision and the works on the classical theory of clubs. In his work the author studies the role of community in migration dynamics.

Nevertheless, in another branch of literature, migration is studied as a temporary phenomenon. Some theoretical papers have supported this approach. Hill (1987), develops a life-cycle model of immigrant behaviour to determine total time allocated to home-country and foreign-country residence, and the number of migratory trips. In his paper Hill obtains two important results: a) on the one hand, lifetime participation in the foreign labour market will be more sensitive to changes in the home wage than to equal, but opposite, changes in foreign wage. This fact means that policies to control migration flows are more effective in the country of origin than in the host country ; b) on the other hand Hill finds that changes in travelling costs have predictable effects on the number of border crossing but not for the total time spent in the foreign labor market. Djajic and Milbourne (1988), explicitly stress the importance of considering migrations as a temporary phenomenon, and develop a life-cycle model to study the effect of wage differentials in determining migration flows and their final effect on equilibrium wages. Djajic (1989) examines the behaviour of utilitymaximizing migrants in a system of guest-worker migration. The paper stresses the difference between permanent and temporary migration: while a permanent migrant is primarily interested in the real-wage differential between countries of immigration and emigration, a guest worker's decision to migrate depends 
on both real and nominal differential. The relative importance of the nominal differential is found to be inversely related to the degree of concavity of his instantaneous utility function. Berninghaus and Seifert-Vogt (1988), develop a model in which each guest worker plans to accumulate capital in the host country (hypothesis supported also by Piore, 1979) for investment in the home country after return migration. But, due to incomplete information about the economic variables of the host countryand in the home country as well, each immigrant might prolong his stay: in other words, temporary migration might turn into permanent migration. Stark (1992), uses the theory of relative deprivation and arguments of risk spreading to explain why migrants may return to a less rich economy or region. Dustmann $(1995,1997)$ shows that "further motives for a return migration are a high purchasing power of the host country currency in the migrant's home economy, and higher returns to human capital, accumulated in the host country, in the home economy". Moreover, some empirical estimates support the temporary approach showing that "more than two thirds of the foreign workers to the Federal Republic have returned" (Böhning, 1987); or that "85\% of Greeks have migrated to West Germany gradually returned" (Glytsos, 1988). Other papers about US migration, report that between 1908 and 1957 about 15.7 million persons immigrated to the US and about 4.8 million aliens emigrated (Jasso and Rosenzweig, 1982) or that about one third of legal immigrats to the US re-emigrated in the 1960's (Warren and Peck, 1980). In line with these results Dustmann (2003) analyses optimal migration durations despite persistently higher wages in the host country. An important result is that, if migration is temporary, the optimal migration duration may decrease even if the wage differential grows larger (in details, they find an inverse U-shaped relationship between durations and wages). This is due to the higher weight of marginal utility of wealth (income effect) than which one of the marginal value of staying in the host country (relative wage effect). This result is verified also when each immigrant must decide simultaneously about the optimal migration duration and their after-return activity (Dustmann, 2002). Since temporary migration is an important feature of migration penomenon, some papers have tried to study the role of migration policies to control inflows and outflows. About this, Faini (1996) emphasizes how "allowing for the effect of migration controls on the return migration can provide the key to understanding (1) why return policies were quite ineffective and (2) why return propensities declined after 1974 despite the increase in the host countries' employment". Moreover, in a recent work, Magris and Russo (2005), show that there exists a trade-off between frontiers closure and migration duration: in particular, they show that a strict regulation of entries decreases both inflows and outflows, and its net impact on the number of foreign residents is undetermined.

Therefore, as Berninghaus and Seifert-Vogt (1988) showed "temporary migration might turn into permanent migration": on the one hand, uncertainty over the economic condition in the host country as well in the home country might prolong the optimal duration of migration (Berninghaus and SeifertVogt, 1990, page 205), on the other hand during the first years of living in the host country a sociocultural assimilation of the migrants takes place that might change their preferences. The assimilation in the host country is accompanied by observed disintegration in the home country. "Consequently temporary migration might turn into a permanent migration as a result of cultural assimilation too" (see also Piore, 1979). Moreover, since uncertainty might prolong the duration of stay, and since incomplete information alone "suffices to induce migration flows even between countries that can be regarded as "identical" from an economic point of view" (Berninghaus and Seifert-Vogt shown, 1990, page 28 ), uncertainty is an important key-element that should be taken into account. 
Given this focal point (uncertainty), given that migration choice can be postponed and given that temporary migration might turn into permanent migration, we have all the ingredients to use real option approach in line with Burda's work but also with the literature on temporary migration: we introduce a real option model with combined entry and exit strategies. Its advantages are the following: a) real option stresses the role of uncertainty also because it is one of the pillars of the approach; b) it develops a countinuous time model with respect two period models that are the benchmark ${ }^{4} ; \mathrm{c}$ ) the analysis of duration with entry-exit strategies is as if two permanent decisions were combined in an unified one. This idea could be more in line with a histersis process described by duration of migration.

Therefore, so far we have introduced the idea behind the peculiar model adopted. Now we must clarify the main variables used in our approach. Generally, in theoretical economic literature, migration choice depends on the wealth difference between the country of origin and the host country, because mainly "people migrate in order to increase their welfare ${ }^{15}$. Therefore, the wage differential between the host country and the country of origin is assumed as the main variable affecting migration (Todaro, 1969; Langley, 1974; Hart, 1975; Borjas, 1990, 1994), even if it is not sufficient to totally explain migrant behaviour: in fact, evidence seems to stress the focal role of community networks in the migrant's choice (Boyd, 1989; Bauer and Zimmermann, 1997; Winters et al., 2001; Bauer et al., 2002; Coniglio, 2003; Munshi, 2001, 2003; Heitmueller, 2003). Moretti (1999), for example, with an alternative model to Todaro's, finds evidence that both the timing and the destination of migration could be explained by the presence of social networks in the host country. Additionally population size and migration are important also because a congestion effect can appear, given that the number of users of public services reduces productivity gains, as Braun (1993), Krichel and Levine (1999) and Clemente et al, (2008) note. In line with this evidence, Bauer et al. (2002) examine the relative importance and interaction of two alternative explanations of immigrant clustering: 1) network externalities and 2) herd behaviour. The same theme is also studied in Epstein and Gang (2004), where the authors analyse the roles "other people" play in influencing an individual's potential migration decision. In fact, the moment immigrants settle in a country, they have to acquire a place in that new society. This is true not only for physical needs such housing, but also in the social and cultural sense. It this context, it is crucial the role assumed by integration process, by which immigrants become accepted into society, both as individuals and as groups. Integration is not only taking place - as is often supposed - at the level of the individual immigrant, but also at the collective level of the immigrant group. In fact, when a immigrant enters a new society, he begins to build a group of people (or he enters a group if is already exists), based on affinities, religions and the same way of life: this group is generally called "community". In addition, the process of integration is related to the level of institutions, which come in two broad types. The first are general public institutions of receiving societies or cities, such as the education system or institutional arrangements in the labour market or the dimension of the urban area in which the community develops. The second kind of institution belongs to specific types of immigrant group themselves, such as religious or cultural institutions. This aggregate of individuals that uses, like a family, the same goods, "deriving mutual benefit sharing [...] production costs, the members' characteristics, or a good characterised by excludable benefits", can be modelled by following economic theory of "club" (Sandler and Tschirhart, 1980; Buchanan, 1965; Berglas, 1976, Vergalli, 2008). Therefore, the role of "other people" seems to be crucial to complete wage differential effect on migration choice in a structural model. For this we 
introduce the role of community in the entry and exit strategies of migration, trying to discover what happens in migration choice when we assume temporary migration in a real option framework. This paper is organised as follows: section 2 presents the model and the basic assumptions; section 3 develops the theoretical framework that combines real option theory and the network effects, namely the optimal migration strategy in the presence of positive and negative externalities and shows the main results; finally, section 4 summarises the conclusions.

\section{The Model}

This section presents a continuous-time model of migration where the differential benefits of migration, including the wage differential, evolves in a stochastic manner over time and there is ongoing uncertainty.

It is possible to summarise the main assumptions:

1. There exist two countries: the country of origin where each potential migrant takes his decision and the host country.

2. At any time $t$ each individual is free to decide to migrate to the new country. Individuals discount the future benefits at the interest rate $\rho$.

3. All immigrants are identical, are infinitely-lived, or choose vicariously for their descendants who will remain in the receiving country forever ${ }^{6}$. Their size $d n$ is infinitesimally small with respect to the total number of inhabitants (VEDI NOTA) ${ }^{7}$.

4. Each individual enters a new country undertaking a single irreversible investment which requires an initial sunk cost $K$. If he wanted to return to his country, he must pay another sunk cost, called $E^{8}$.

5. The migrant faces some known constant variable costs of operation, called $C^{9}$. This cost might include legally required termination payments for houses, the buildings of the community he decided to sustain, the costs for buying a return ticket to his country and the loss of some businesses underway.

6. The wage differential for each migrant, called $x$, follows a geometric diffusion process (VEDI NOTA $)^{10}$ :

$$
d x=\alpha x d t+\sigma x d w
$$

with $x_{0}=x$ and $\alpha, \sigma>0$. The component $d w$ is a Weiner disturbance defined as $d w(t)=\varepsilon(t) \sqrt{d t}$, where $\varepsilon(t) \sim N(0,1)$ is a white noise stochastic process (see Cox and Miller, 1965). The Weiner component $d w$ is therefore normally distributed with zero expected value and variance equal to: $d w \sim N(0, d t)$. From these assumptions and from the (1) we know that $E[d w]=0 ; E[d x]=\alpha x d t$.

7. In the host country there is a community of ethnically homogeneous individuals. Each individual becomes a member (finding a job) instantaneously when he enters the host country ${ }^{11}$.

8. The community net benefit function for each member is an inverse Ushaped with regards to the number of members and can be modelised by using "theory of clubs" as in Vergalli (2008) and also in line with Bauer 
et al. (2002). Formally, in a given instant $t$, the migrant's utility function can be reduced to ${ }^{12}$ :

$$
U(x, n)=x+\theta u(n)
$$

where $\theta$ is a scale factor. The function $u(n)$ is twice continuously differentiable in $n$, and it is increasing over the interval $[0, \bar{n})$ and decreasing thereafter. The assumption of an inverse U-shaped benefit function combines network effect (in line with Moretti, 1999; Munshi, 2003) and congestion and competition effects in the host country (Bauer et al., 2002; Clemente et al., 2008). The benefit function is separable in $x$ and $u(n)$.

\section{Results}

To solve the optimal decision problem of a potential immigrant or emigrant, we use standard real option apporach as showed in Dixit-Pindyck (1994, pp. 216-218) or in Dixit (1989, page 625). We must distinguish between the value of staying idle $\left(V_{0}\right)$ and the value of belonging to the host country, $\left(V_{1}\right)$.

Let us start with the idle entrant: the resulting equation for $V_{0}(x)$ is:

$$
\frac{1}{2} \sigma^{2} x^{2} V_{0}^{\prime \prime}(x)+\alpha x V_{0}^{\prime}(x)-\rho V_{0}(x)=0
$$

Its general solution:

$$
V_{0}(x)=A_{1} x^{\beta_{1}}
$$

where $A_{1}$ is a constant to be determined, and $\beta_{1}>1$ is a known constant whose value depends on the parameters $\rho, \sigma$ and $\alpha$. This value is valid in the interval in which each individual remains at home. Let us call $x_{h}$ the threshold level of wage differential that triggers entry. Therefore, (18) is valid over the interval $\left(0, x_{h}\right)$.

Now, let us consider the value of living in the host country for the migrant:

$$
\frac{1}{2} \sigma^{2} x^{2} V_{1}^{\prime \prime}(x, n)+\alpha x V_{1}^{\prime}(x, n)-\rho V_{1}(x, n)+x-C+\theta u(n)=0
$$

The general solution of this equation is:

$$
V_{1}(x, n)=B_{2} x^{\beta_{2}}+\frac{x}{\rho-\alpha}+\frac{\theta u(n)-C}{\rho}
$$

where the last two terms are the value of remaining in the country despite any losses and the first two terms are the value of the option to abandon the country.

If (19) is the value of stay in the host country, it must be valid over a given threshold $x_{L}$ that triggers entry. Therefore, (19) is valid for $x$ in the range $\left(x_{L}, \infty\right)^{13}$.

Equations (18) and (19) can be solved by using ordinary value-matching and smooth-pasting conditions showed in the appendix (equations (20), (21) and $(22),(23)$ respectively). Therefore, as far as real option framework is concerned, we obtain two threshold wages: an upper bound $\left(x_{H}\right)$ and a lower bound $\left(x_{L}\right)$ :

- if the threshold $x$ rises above the upper bound $x_{H}$, then the immigrant enters the host country; 
- if the threshold is below $x_{L}$, then the migrant returns to his country of origin;

- in the between, in the interval $\left(x_{L}, x_{H}\right)$, each individual remains idle in the host country (if he has emigrated yet) or in his country of origin (if he still in his country). This kind of inaction is a hysteresis process that magnifies and partially explains the duration of migration ${ }^{14}$.

To better analyse the hysteresis process in migration decision in a entryexit real option framework and how the community of immigrants could affect migration flow and in particular its duration, we define the following function, by using the solutions (17) and (5):

$$
\begin{aligned}
G(x, n) & =V_{1}(x, n)-V_{0}(x)= \\
& =-A_{1} x^{\beta_{1}}+B_{2} x^{\beta_{2}}+\frac{x}{\rho-\alpha}+\frac{\theta u(n)-C}{\rho}
\end{aligned}
$$

where $G(x)$ represents on the interval $\left(w_{L}, w_{H}\right)$ the migrant's incremental value of migrating. If we do not take into account the presence of the community, equation (28) becomes:

$$
\begin{aligned}
G(x) & =V_{1}(x)-V_{0}(x)= \\
& =-A_{1} x^{\beta_{1}}+B_{2} x^{\beta_{2}}+\frac{x}{\rho-\alpha}-\frac{C}{\rho}
\end{aligned}
$$

The general shape of $G(x, n)$ with community, obtained by (7) - blue line - and the particular case without community benefit $(G(x)),(8)$ - dotted line, are shown in figure 1.

[figure 1 about here]

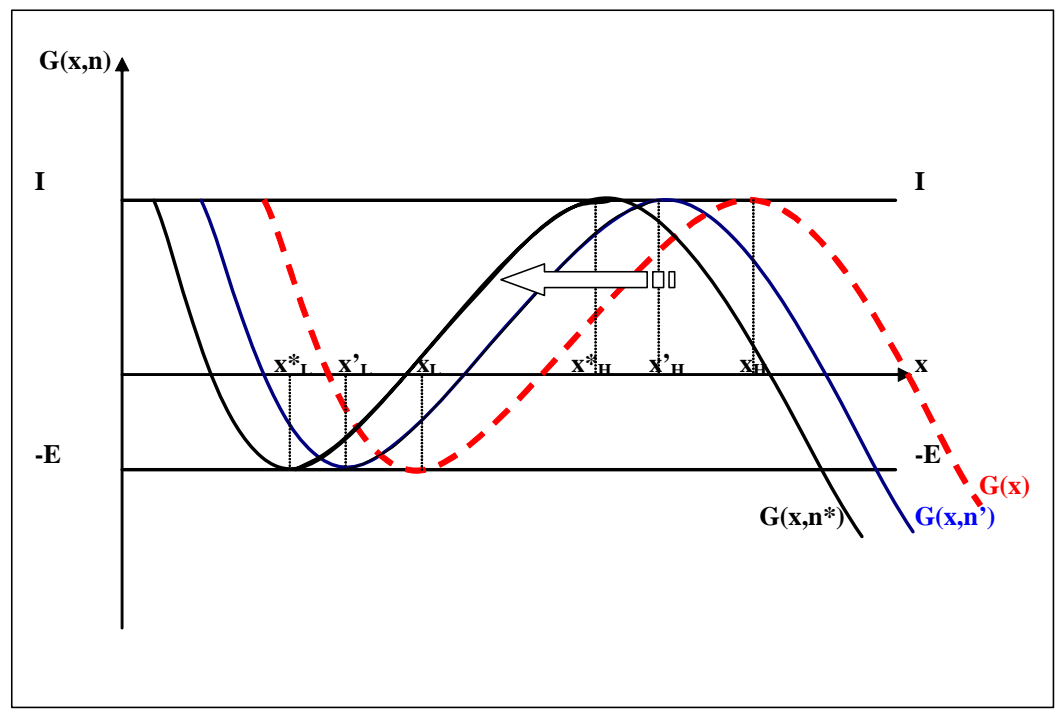

Figure 1: Entry and Exit Strategies

The $G(x, n)$ curves show the optimal threshold levels for given numbers of immigrant in the community. When the shock is between the upper $\left(x_{H}\right)$ and the lower $\left(x_{L}\right)$ bound nothing happen and each immigrant stays still. This 
happens in the case without community (red-dotted line) and with community (continuous line), as well. Let us stress that when the shock, that moves according to (1), touches or crosses (on the abscissa) the upper (lower) bound, there is a new entry (exit) of immigrants in the host country. In the presence of community, this fact implies a change in the total number of members and the $G(x, n)$ function moves according the new dimension. Vergalli (2008) and Moretto and Vergalli (2008) have showed that there exists an optimal level of individuals $\bar{n}$ that defines the optimal dimension of community in which the benefit is at the maximum. Therefore, if the dimension of community is lower than the optimal level, then each individual increases the benefit to migrate due to network effects. For this a new entry moves the $G(x, n)$ curve to left, changing the entry-exit thresholds, until the optimal dimension $\bar{n}$ is reached. After that point the benefit added by each new member of the community decreases until is reached marginal benefit added equal to zero. This is due to the combination of congestion and competition effect that decrease the marginal benefit of each new member. This effect moves the $G(x, n)$ curve to right, until the network and congestion effects are offset.

Given the focal role of the two triggers $\left(\left(x_{H}\right)\right.$ and $\left.\left(x_{L}\right)\right)$, we calculate them by using real option methodology (the proofs in appendix). To solve the problem for both the cases (equation (7) and (8)), we must adjust $A_{1}$ and $B_{2}$ until $G(x)$ (or $G(x, n)$ ) becomes tangent to the horizontal lines $-E$ and $K$ (in figure 1), and the respective points of tangency define $x_{L}$ and $x_{H}$. Technically speaking, this tangency comes from the value-matching and smooth pasting conditions that imply that the entry-exit triggers must be optimal when the migrant's incremental value of migrating is equal to the entry-exit costs. In the general case, the optimal thresholds are:

$$
\begin{aligned}
x_{H} & >C+\rho K \equiv C_{H} \\
x_{L} & <C-\rho E \equiv C_{L}
\end{aligned}
$$

where $C_{H}$ and $C_{L}$ are the marshallian triggers ${ }^{15}$ for entry and exit, respectively.

Let us notice that the optimal triggers are respectively greater and lower than the marshallian cases. This implies two things: on the one hand, at a differential wage between the two limits, an idle immigrant does not emigrate and an immigrant in the host country does not return home; on the other hand, the uncertainty widen the marshallian range of inaction. Let us stress some comments about (9) and (10): as both $K$ and $E$ tend to zero, both $x_{H}$ and $x_{L}$ tend to the common limit $C$. Thus sunk costs are essential to hysteresis and therefore to migration duration. Moreover, if only one of $K$ and $E$ tends to zero, while the other stays positive, both inequalities (9) and (10) remain strict. Indeed, even if $E$ is nil, the exit threshold $x_{L}$ remains below $C$. Each immigrant knows that if he remains in the host country, he can avoid incurring $K$ to reentry in future if the differential wage will increase again. He prefers to incur some current loss in order to preserve this kind of option.

In the peculiar case with community, the threshold levels become:

$$
\begin{aligned}
& x_{H}^{*}>C+\rho K-\theta u(n) \equiv C_{H}-\theta u(n) \equiv C_{H}^{\prime}(n) \\
& x_{L}^{*}<C-\rho E-\theta u(n) \equiv C_{L}-\theta u(n) \equiv C_{L}^{\prime}(n)
\end{aligned}
$$

Let us notice that, given that by definition $u(n) \geq 0$, thus in both the cases $x_{H} \geq x_{H}^{*}$ and $x_{L} \geq x_{L}^{*}$. Therefore, the effect of community in migration 
duration is that it reduces the entry-exit thresholds and thus it speeds up entry and delays exit of immigrants.

Following Dixit (1989) it is possible to stress that, if $E>C / \rho$, than the immigrant will never go home. Nevertheless, $x_{H}$ does not go to infinity.There exists a finite differential wage that entails a high value of migration to the host country, impossible to get out of. For this, the option to exit must be worthless. Therefore, $B_{2}$ of equation (19) must be imposed equal to zero. Then, we can obtain:

$$
x_{H}=\left[\frac{\rho-\alpha}{\rho}\right]\left[\frac{\beta_{1}}{\beta_{1}-1}\right] C_{H}
$$

or, in the case with community:

$$
x_{H}^{*}=\left[\frac{\rho-\alpha}{\rho}\right]\left[\frac{\beta_{1}}{\beta_{1}-1}\right] C_{H}(n)
$$

Moreover, if $\mathrm{K}$ goes to infinity, the entry option becomes worthless and $A_{1}$ is nil. Then we can obtain

$$
x_{L}=\left[\frac{\rho-\alpha}{\rho}\right]\left[\frac{\beta_{2}}{\beta_{2}-1}\right] C_{L}
$$

or, with community:

$$
x_{L}^{*}=\left[\frac{\rho-\alpha}{\rho}\right]\left[\frac{\beta_{2}}{\beta_{2}-1}\right] C_{L}(n)
$$

Let us notice that when $\sigma \rightarrow 0$ this implies that $x_{L}^{*} \rightarrow C_{H}(n)$ and $x_{L}^{*} \rightarrow$ $C_{L}(n)$. This implies that, in the absence of uncertainty, only the Marshallian zone of inaction remains.

Let us consider the comparative statics ${ }^{16}$ of $x_{H}$ and $x_{L}$ with respect to $C$, $K$ and $E^{17}$. Our comments are the following: i) as $C$ increases, both $x_{H}$ and $x_{L}$ increase; ii) when $K$ increases, $x_{L}$ decreases and $x_{H}$ increases: that is, the hysteresis effect becomes more pronounced and this means that the duration increases. Similar effects stem from $E$; iii) if we keep $\sigma$ at a positive level and let $K \rightarrow 0$, we have $d x_{H} / d K \rightarrow \infty$ and $d x_{L} / d K \rightarrow-\infty$. That is, when there is uncertainty, hysteresis emerges very rapidely even for small sunk costs. Similar results when $L \rightarrow 0$.

\subsection{The Role of Community in Entry-Exit Strategy}

The following comments are obtained by comparing the entry-exit strategy without community (8) with respect the same strategy with community (7) and by looking at figure 1. The role of the community for the entry-exit migrant's choice has the following effects:

1. the greater the number of members of the community ${ }^{18}$, the lower the trigger value $x_{H}$ at which each individual decides to migrate (for $n<\bar{n}$ ). This fact implies that the higher the number of members for $n \in(0, \bar{n})$, the earlier the migration starts;

2. the greater the number of members of the community, the lower the trigger value of exit $x_{L}$. This fact magnifies the phenomenon of hysteresis to remain in the host country even if the level of the migrant's wage is low. And the greater the benefit coming from the community, the lower the level of wage that each member needs to remain, because of a high network effect. Therefore, if the value of the utility function is sufficiently high, the individual will remain for low level of wage. 
3. Comparative statics have showed that the migration thresholds $x_{H}$ rises and $x_{L}$ falls with the investment cost $K$. This important interaction between the costs and thresholds should also be intuitive upon reflection. The individual abandons the community with some reluctance because of his option value. By staying in the community, he avoids incurring the investment cost once again should the wage process become sufficiently favorable in the future. Therefore, the larger the investment cost, the larger is this option value and the greater is the reluctance to abandon. The mirror image result, namely, that the migration threshold $x_{H}$ rises and $x_{L}$ falls as the abandonment cost $E$ increases, is perhaps even clearer. The individual is more reluctant to undertake the project if he might have to incur a greater cost of shutting it down in the future. The role of the community consists in modifying the effect of a change in $K$ : if the migration cost increases, the entry threshold $x_{H}$ raises lower than in the case of community's absence and the exit's threshold falls more than in the case of no community.

4. The effect of increasing uncertainty: In Berninghaus and Seifert-Vogt shown (1990) the authors showed that a country becomes more attractive for immigration if the "uncertainty" in the quality of life distribution, $[. .$.$] increases. Furthermore, they also demonstrated (Berninghaus$ and Seifert-Vogt, 1987) how the result could be interpreted in the direction of decreasing information. In opposite, it is possible to show the real option approach applied in our framework, shows that a rise in uncertainty increases the threshold level and therefore postpones the entry of immigrants: therefore, that country becomes less attractive.

In conclusion, reassuming comments 1 and 2, the benefit of community:

- from the one hand decreases the trigger level of entry. In this manner more immigrants decide to migrate;

- from the other hand reduces the exit threshold. This fact implies that the immigrants are locked-in the host country.

These two effects increase the number of immigrants in the host country, the duration of their stay and inducing a higher unemployment. Therefore,

Proposition "the existence of a community of immigrants in the host country magnifies the hysteresis' phenomenon. This fact explains migration inflows in presence of high unemployment rates and low wages".

\section{Numerical Results}

This part is devoted to support our theoretical results with some numerical simulations. We have assigned some values to the parameters used and to do this, we refer to Dixit and Pindyck (1998, page 8). Moreover, we have normalized $\mathrm{C}$ to 1 and we have introduced a simple $u(n)$ function to better describe the threshold effect. For the sake of simplicity, $u(n)$ is maximum in $n=50$ and minimum in $n=0$ and $n=100$, as well. Let us show the optimal threshold level $x_{H}$ (figure 2) and $x_{L}$ (figure 3 ) with respect the volatility of differential wage and the dimension of the community. 


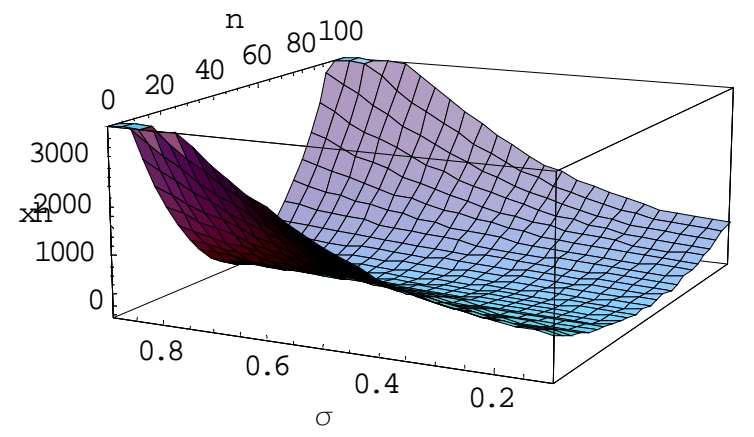

Figure 2: Optimal threshold $x_{H}^{*}$ with respect the number of immigrants $n$ and volatility $\sigma$.

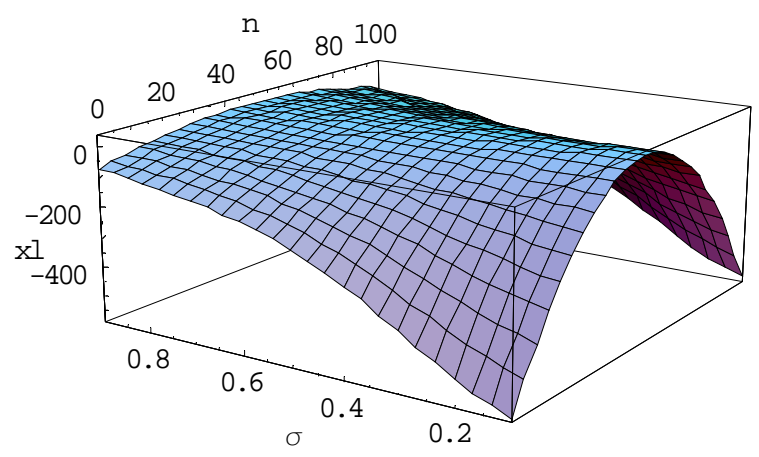

Figure 3: Optimal threshold $x_{L}^{*}$ with respect the number of immigrants $n$ and volatility $\sigma$.

From figure 2 and 3 is possible to stress that, in both the cases, the higher the volatility, the higher the entry-exit threshold levels. Moreover, the higher the dimension of community (for $\mathrm{n}<\bar{n}$ ) the lower the optimal threshold required to migrate. These results are perfectly in line with comparative statics showed in previous sections. If instead we analyse the combined effect of volatility and community, we see that a high $\sigma$ reduces the network effect for the lower level and increase the effect for the upper threshold. In fact, on the one hand the volatility effect increses the threshold level required to migrate, (more uncertainty needs a higher wage differential), on the other hand, the network effect decreases the entry-exit triggers, but when the first effect is strong, it dominates the second one: the intuition is that the community is unable to help each new immigrant if there are strong shocks in the labour market.

In figure 4 and 5 we show comparative statics with respect variable n (i.e., netweork effect) and C (i.e. operative costs). The results are perfectly in line with theoretical economics: community effect reduces entry and exit triggers and therefore increases the number of immigrants, while everiday costs reduces immigrants flows. 


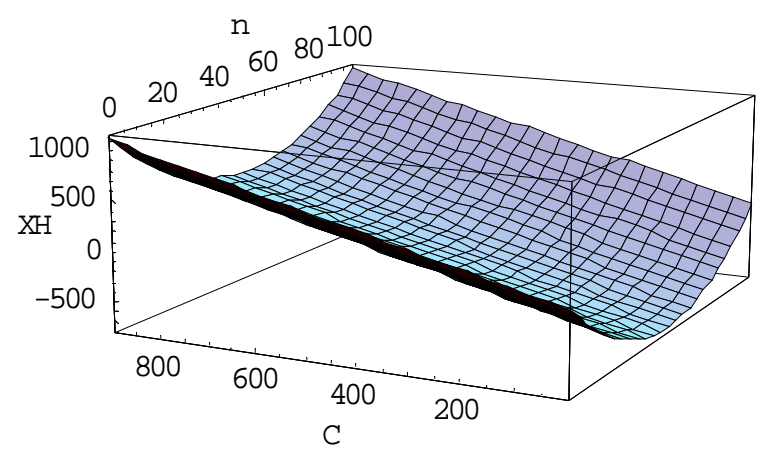

Figure 4: Optimal threshold $x_{H}^{*}$ with respect the number of immigrants $n$ and C.

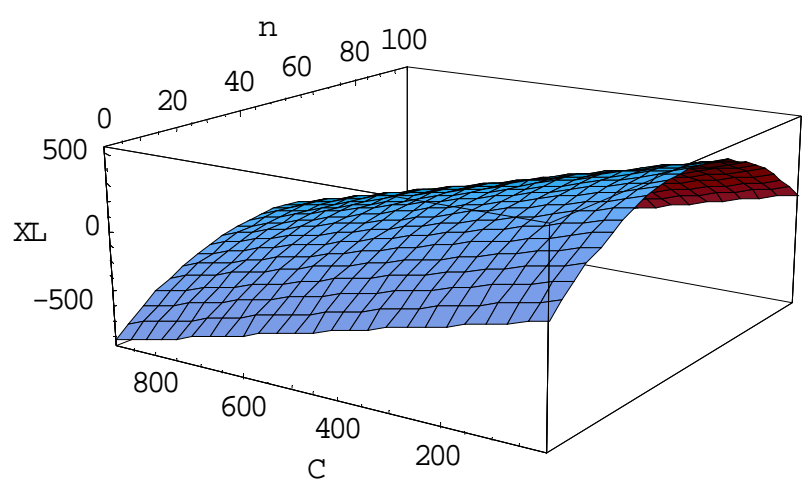

Figure 5: Optimal threshold $x_{L}^{*}$ with respect the number of immigrants $n$ and C.

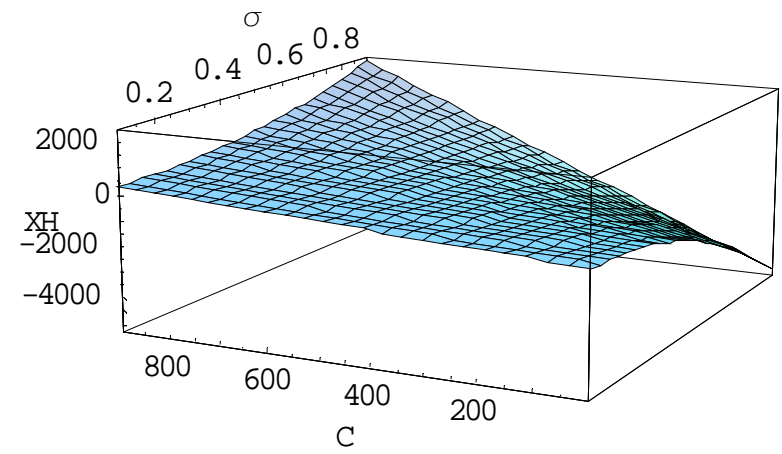

Figure 6: Optimal threshold $x_{H}^{*}$ with respect the number of immigrants $n$ and volatility $\sigma$. 


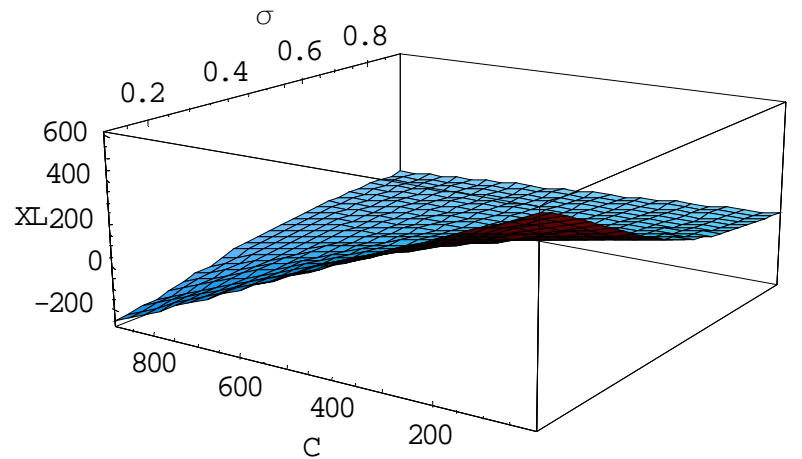

Figure 7: Optimal threshold $x_{L}^{*}$ with respect the number of immigrants $n$ and volatility $\sigma$.

More interesting, from a political point of view, is the

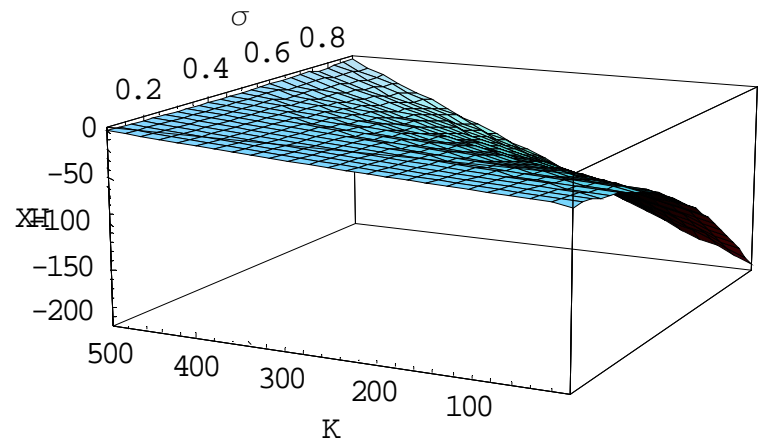

Figure 8: Optimal threshold $x_{H}^{*}$ with respect volatility $\sigma$ and $K$.

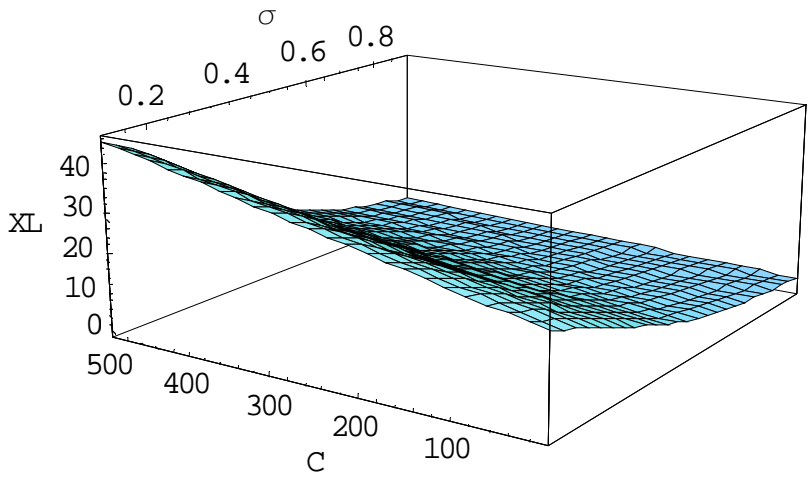

Figure 9: Optimal threshold $x_{L}^{*}$ with respect volatility $\sigma$ and $E$. 


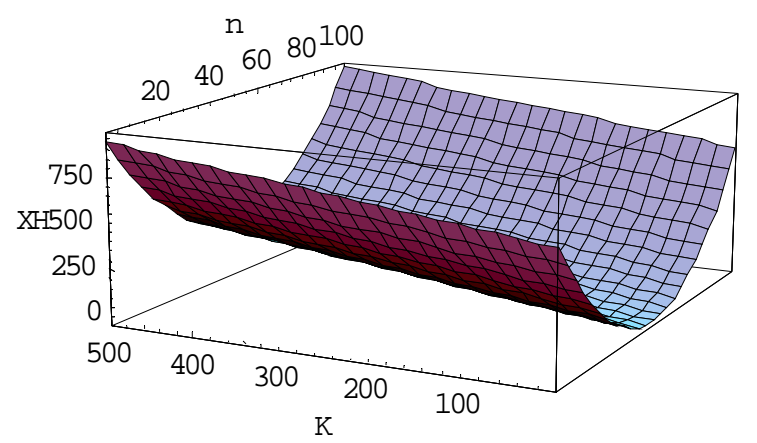

Figure 10: Optimal threshold $x_{H}^{*}$ with $\rho=0.5$ and with respect volatility $K$ and $n$.



Figure 11: Optimal threshold $x_{L}^{*}$ with $\rho=0.5$ and with respect volatility $E$ and $n$.

\section{The Results in Economic Literature}

\subsection{Harris Todaro paradox}

In two seminal papers, Todaro (1969) and Harris and Todaro (1970) have developed a canonical model of rural-urban migration. The main idea is quite simple since it says that migration will occurs as long as the urban expected income (i.e. income times the probability to find an urban job) is higher than the rural one. These papers have been so influential that they are referred in the literature to as the Harris-Todaro model. One of the main issues raised in these papers was that creating urban jobs may increase rather than decrease urban unemployment because of the induced negative effect on rural migration, which may outweight the positive effect of creating jobs (Todaro, 1976). This is referred to as the Todaro paradox.

The paradox is due to the assumptions that in choosing between labour markets, risk-neutral agents consider expected wages; that the probability of obtaining urban employment is approximated by the ratio of urban jobs to the urban labor force; and that the urban wage rate is considerably and consistently higher than the rural wage rate. Under these assumptions, inter-labour market (rural-urban) equilibrium mandates urban unemployment. This unemployment ensures that the expected urban wage is equal to the rural wage (which is assumed constant throughout). The repercussion of this simple set of assumptions is that contrary to received wisdom, once the migration response is factored in, 
several policies aimed at reducing urban unemployment will raise urban unemployment rather than reduce it. In the Harris-Todaro model migration is regarded as the adjustement mechanism by which workers allocate themselves between different labor markets, some of which are located in urban areas and some in rural areas, while attempting to maximize their expected incomes. The effects of the model described above, change the magnitudo and the sign of the Harris-Todaro (1970) paradox: by reducing the threshold level to migrate (i.e. the minimum wage) with respect to a labour market without community, the unemployment rate is not so efficient to counterbalance the migration inflows. In this case the Todaro paradox is diluted. This effect is similar to a reduction of "unemployment benefit" imposed by the goverment as descirbed in Zenou (2005). In his framework, a Todaro paradox exists if a reduction in the urban unemployment benefit (exogenous variable and policy instrument) leads to an increase of both urban employment and unemployment. This is a paradox since a reduction in the unemployment benefit has the natural effect to increase urban employment but the counterintuitive effect to also increase urban unemployment.

In the case of a search-matching model where wages are bargained, a Todaro paradox may exist if a condition on parameters is satisfied. Indeed, the benefit of community has a direct positive effect on bargained wages. As a result, because it is cheaper and thus more profitable to hire a worker, more firms enter the urban labor market and more jobs are created, and thus rural-urban migration increases. However, when the community benefit decreases, there is also a direct negative effect on migration since urban wages are lower and thus less rural workers migrate. The net effect is thus ambiguous. A condition that guarantees that the indirect positive effect on migration is larger than the direct negative effect leads to a Todaro paradox since a reduction in community benefit increases in this case both urban employment and unemployment.

\subsection{Effects of community in countries with centralised wage- setting and no labour mobility}

Another insight rises with respect to a two-countries centralised wage-setting framework (Boeri and Brücker, 2005).

[figure 2 about here]

In presence of wage compressing institutions, international migration can reduce unemployment also in the low-productivity (high-unemployment) regions. This additional "greasing the wheels" effect of migration is visually characterised in the above diagram. The panel on the left-hand side shows the market-clearing wage prevailing in the dynamic regions (called here the Rich or North) which is also paid - due to the imposition of the same contractual minima throughout the country - in the Poor or South. At the initial equilibrium, the South experiences unemployment as the Northern wage acts as a binding minimum wage. Migration has two useful functions in this context. On the one hand, it increases employment and reduces wages in the North by shifting to the right labour supply (as shown by the blue line, S'). On the other hand, migration, by acting on Northern wages, reduces labour costs also in the South (from w to w*) allowing partially to absorb its unemployment pool there (which shrinks from $\mathrm{u}$ to $\mathrm{u}^{*}$ ). As observed above, the community reduces the entry-exit threshold, that is, the centralised minimum wage. Therefore, the effect is an increase in the supply to the red dotted line, by increasing the number of immigrants. The consequence is a rise of the employment $\left(\mathrm{E}^{\prime \prime}\right)$ in the rich region and a reduction of the unemployment rate in the poor region $\left(u^{\prime \prime}\right)$. 


\section{Some extensions}

So far, we have studied the role of the community in the entry and exit of a migrant, developing a model quite similar to Burda and implementing an extension taken from the theory of club. We have observed that a homogeneous community of individuals reduces the trigger level at which the individual decides to migrate and also reduces wage level at which each migrant wants to go back. We have assumed that all the individuals are homogeneous and we haven't take into account any policy choice. But what happens if the individuals are heterogenous? Now we generalise the model in a simple manner, considering two possible implementations.

Taking into account the possibility of different skills among the migrants, we could assume that they are able to gain higher wages, the higher their levels of skill. That is, in a simple manner we could assume that the value of migrating in the host country is:

$$
V(x, n)=E_{0}\left[\int_{0}^{\infty}\left(\Psi_{i} x+\theta u(n)\right) e^{-\rho t}\left|n_{0}=n, \theta_{0}=\theta, x_{0}=x\right|\right]
$$

with $\Psi_{i}>\Psi_{j}{ }^{19}$, if the skill level $i$ is greater than $j$.

By this function and following the previous method, it is possible to demonstrate that the first inflow would be composed of high skills, because of a greater benefit for the same shock $x$. Furthermore, for the same reason they would remain more time than the others. Nevertheless, increasing the number of the community's members, the benefit should increase, ceteris paribus. This fact should mean a reduction of the threshold level and the entry also of low-skill immigrants. A possible policy for selecting the migrants'skills, could consist in increasing entry costs, as Urrutia (2001) suggests. However, as we have seen, this policy option would increase the hysteresis phenomenon of remaining in the community. Furthermore, the policy makers generally help the integration of new groups because of their lower possibilities. Although this policy choice is right for ethic reasons, it would not only stimulate migration, increasing the phenomenon of hysteresis, but also reduce the average level of migrants' skills.

Governments can not only deploy measures to reduce the uncertainty facing potential investors, they can also create uncertainty through the prospect of policy change. This feature of the policy process is relevant in migration analysis because a new law could increase or reduce the costs of integration of all immigrants. It is commonly believed that expectations of shifts in policy can have powerful effects on decisions to invest. We show a possible analytical implementation in appendix C.

\section{Conclusions}

This work analyses the role of combined entry and exit strategies in the migration process. It develops a real option model in which the community of immigrants in the host country is described as a club and the immigrant's benefits is a U-shaped function, depending on the dimension of the district. This framework is in line with Vergalli (2006). In particular, this paper applies some extensions taken from Dixit and Pindyck (1993, pp. 217-222) regarding the combined entry and exit strategies of migrants: there exists a threshold that triggers the entry and a second that triggers the return to the country of origin. The theoretical results show that the phenomenon of hysteresis is amplified by 
the existence of a community both in the entry case and in the exit case. Furthermore, the community can reduce the minimum wage level required to trigger both exit and entry: this fact could explain why in some cases it is possible to observe migration inflows with a low wage differential and also with underunemployment as previously shown by Todaro (1970). This important result shows some theoretical implications: in a framework with centralised wage-setting and no labour mobility (Boeri and Brücker, 2005), the consequence is a rise of the employment in the rich region and a reduction of the unemployment rate in the poor region, because of a reduction minimum wage and an increase in the labour supply. Finally the paper, by adding heterogeneity among immigrants, shows that the imigrants characterized by high skills, should be the first wave to migrate because of the higher expected wage; this fact increases the dimension of community and, reducing the threshold level, pushes the entry of the low skills immigrants. 


\section{Notes}

${ }^{1}$ In this respect, see Chiswick (1978, 1980), Borjas (1985), Bell (1997), Friedberg (2000), Barth et. al (2004).

${ }^{2}$ See Berninghaus and Seifert-Vogt (1988) and Piore (1979).

${ }^{3}$ Investment is defined as the act of incurring an immediate cost in the expectation of future payoff. However, when the immediate cost is sunk (at least partially) and there is uncertainty over future rewards, the timing of the investment decision becomes crucial (Dixit and Pindyck, 1994, p.3).

${ }^{4}$ See for example Berninghaus and Seifert-Vogt (1988, 1990), Karayalcin (1994), Dustmann (2002, 2003, 2004).

${ }^{5}$ Khwaja, Y., "Should I Stay or Should I Go? Migration Under Uncertainty: A Real Option Approach", mimeo, March, 2002

${ }^{6}$ It is possible to show that the "sudden death" formulation is a very natural generalisation of the infinite-life case (Dixit and Pindyck, 1993, p.205).

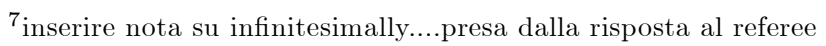

${ }^{8}$ In this manner we explain that temporary migration (i.e. the possibility to return to the country of origin) is assumed but it is the combination of two actions: entry and exit. It is assumed that the two choices must bear sunk costs both for entry and for exit. Therefore, we implicitly suppose that each individuals acts as if chose between two irreversible decisions. This theoretical novelty is in line with histeresis process in temporary migration showed in economic literature.

${ }^{9}$ That could represent the costs of integration.

${ }^{10}$ Nota: vedi risposta al referee....

${ }^{11}$ This hypotesis assumes that each immigrant is able to find a job instantly whenhe/she enters in the host country. Moreover he/she is perfectly integrated in his/her homogeneous community. This assumption is useful to simplify the mathematical analysis, but it is possible to extend this approach by solving the model in a two-stage backward model, as it is done in Moretto and Vergalli (2008). Anyway, the qualitative results do not change. See Vergalli (2008) for further details.

${ }^{12}$ Formally, in line with "theory of clubs" literature, we assume that there exists a common public good $J$, such as churches, cultural centres and houses, belonging to a group of homogeneous individuals. Given that $J$ shows some rigidities, the analysis assumes that this public good is fixed in a given instant $t$ or in the short run. This variable could change in the long run, until an optimal threshold $J^{*}$. In any cases, for a fixed level of $J$ or at the optimal ceiling, the benefit function is an inverse U-shaped function with respect the number of immigrants belonging to the community. Furthermore, if the initial level of the public good is not the optimal one, when $J$ increases the maximum in $\bar{n}($ i.e. $\mathrm{u}(\bar{n})$ ) increases. About this, see Buchanan (1975), Berglas (1976), Cornes and Sandler (1986) or Vergalli (2008) for further details.

${ }^{13}$ In Appendix A, we explain how it is possible to find the value of the parameters of these equations, following the methodology of Dixit and Pindyck. For details, let see Vergalli (2005).

${ }^{14} \mathrm{~A}$ peculiar caveat must be added about the comparison between "hysteresis" and "migration duration". Hysteresis is defined (Dixit, 1989, page 622) as "the failure of an effect to reverse itself as its underlying cause is reversed. For example, the foreign firms that entered the U.S. market when the dollar appreciated did not exit when the dollar fell back to its original level". This definition is often used in industrial economics. Migration duration is in line with Dustmann $(1996,2002,2003,2007)$ and it is the period of stay of an immigrant in the host country. It is easy to understand that, by definition, the migration duration strongly depends on an exit decision of each immigrant. Therefore an hysteresis process increases duration of immigrants.

${ }^{15}$ The mashallian trigger is "the point at which the present value of the benefit exceed the cost of migration", see Anam et al. (2007).

${ }^{16}$ These comparative statics happen in both the cases, with or without community. 
${ }^{17}$ About the differentiation to support our comments, we relegate the details in the appendix.

${ }^{18}$ for a given dimension of $J$.

${ }^{19}$ Without loss of generality, $\Psi$ can be distributed as $\Psi \sim N\left(\bar{\Psi}, \sigma_{\Psi}\right)$. 


\section{A Appendix: Entry and exit strategies}

Let us start with the idle entrant. The resulting equation is a differential equation for $V_{0}(x)$ :

$$
\frac{1}{2} \sigma^{2} x^{2} V_{0}^{\prime \prime}(x)+\alpha x V_{0}^{\prime}(x)-\rho V_{0}(x)=0
$$

This has the general solution:

$$
V_{0}(x)=A_{1} x^{\beta_{1}}+A_{2} x^{\beta_{2}}
$$

where $A_{1}$ and $A_{2}$ are constants to be determined, $\beta_{1}$ and $\beta_{2}$ are the roots:

$$
\begin{aligned}
& \beta_{1}=\frac{1}{2}-\frac{\alpha}{\sigma^{2}}+\sqrt{\left[\frac{\alpha}{\sigma^{2}}-\frac{1}{2}\right]^{2}+2 \frac{\rho}{\sigma^{2}}}>1 \\
& \beta_{2}=\frac{1}{2}-\frac{\alpha}{\sigma^{2}}-\sqrt{\left[\frac{\alpha}{\sigma^{2}}-\frac{1}{2}\right]^{2}+2 \frac{\rho}{\sigma^{2}}}<0
\end{aligned}
$$

We know that the coefficient $A_{2}$, corresponding to the negative root $\beta_{2}$, must be zero. Indeed for $\mathrm{x} \rightarrow 0$ we must avoid that the value of migration could explode. This fact leaves:

$$
V_{0}(x)=A_{1} x^{\beta_{1}}
$$

This value is valid over the interval $\left(0, x_{h}\right)$.

Let us consider the value of living in the host country for the migrant:

$$
\frac{1}{2} \sigma^{2} x^{2} V_{1}^{\prime \prime}(x, n)+\alpha x V_{1}^{\prime}(x, n)-\rho V_{0}(x, n)+x-C+\theta u(n)=0
$$

The general solution of this equation is:

$$
V_{1}(x, n)=B_{1} x^{\beta_{1}}+B_{2} x^{\beta_{2}}+\frac{x}{\rho-\alpha}+\frac{\theta u(n)-C}{\rho}
$$

where the last three terms are the value of remaining in the country despite any losses and the first two terms are the value of the option to abandon the country. Because the value of the abandonment option should go to zero as $x$ becomes very large, the coefficient $B_{1}$ corresponding to the positive root $\beta_{1}$ should be zero. This leaves:

$$
V_{1}(x, n)=B_{2} x^{\beta_{2}}+\frac{x}{\rho-\alpha}+\frac{\theta u(n)-C}{\rho}
$$

this is valid for $x$ in the range $\left(x_{L}, \infty\right)$.

So, following the methodology of Dixit and Pindyck, we could solve (4) and (6) using the conditions of value matching and smooth pasting:

$$
\begin{aligned}
V_{0}\left(x_{H}\right) & =V_{1}\left(x_{H}\right)-K \\
V_{0}^{\prime}\left(x_{H}\right) & =V_{1}^{\prime}\left(x_{H}\right) \\
V_{1}\left(x_{L}\right) & =V_{0}\left(x_{L}\right)-E \\
V_{1}^{\prime}\left(x_{L}\right) & =V_{0}^{\prime}\left(x_{L}\right)
\end{aligned}
$$

and substituting (4) and (6), we have: 


$$
\begin{aligned}
-A_{1} x_{H}^{\beta_{1}}+B_{2} x_{H}^{\beta_{2}}+\frac{x_{H}}{\rho-\alpha}+\frac{\theta u(n)-C}{\rho} & =K \\
-\beta_{1} A_{1} x_{H}^{\beta_{1}-1}+B_{2} \beta_{2} x_{H}^{\beta_{2}-1}+\frac{1}{\rho-\alpha} & =0 \\
-A_{1} x_{L}^{\beta_{1}}+B_{2} x_{L}^{\beta_{2}}+\frac{x_{L}}{\rho-\alpha}+\frac{\theta u(n)-C}{\rho} & =-E \\
-\beta_{1} A_{1} x_{L}^{\beta_{1}-1}+B_{2} \beta_{2} x_{L}^{\beta_{2}-1}+\frac{1}{\rho-\alpha} & =0
\end{aligned}
$$

The four equations determine the four unknow values.

\section{B Analytical Results}

Now, to analyse the effect of the community on the decision to migrate and to return home, we define the following function:

$$
\begin{aligned}
G(x, n) & =V_{1}(x, n)-V_{0}(x)= \\
& =-A_{1} x^{\beta_{1}}+B_{2} x^{\beta_{2}}+\frac{x}{\rho-\alpha}+\frac{\theta u(n)-C}{\rho}
\end{aligned}
$$

where $G(x)$ represents on the interval $\left(w_{L}, w_{H}\right)$ the migrant's incremental value of migrating. If the same function without the presence of the community is:

$$
\begin{aligned}
G(x) & =V_{1}(x)-V_{0}(x)= \\
& =-A_{1} x^{\beta_{1}}+B_{2} x^{\beta_{2}}+\frac{x}{\rho-\alpha}-\frac{C}{\rho}
\end{aligned}
$$

Working with the function $G$ remains useful, and it helps to show its dependence on the option value coefficients. Thus we write $G\left(x, A_{1}, B_{2}\right)$. The valuematching and smooth-pasting conditions are:

$$
\begin{array}{ll}
G\left(x_{H}, A_{1}, B_{2}\right)=K, & G\left(x_{L}, A_{1}, B_{2}\right)=-E \\
G^{\prime}\left(x_{H}, A_{1}, B_{2}\right)=0, & G^{\prime}\left(x_{L}, A_{1}, B_{2}\right)=0
\end{array}
$$

Note that

$$
G^{\prime \prime}\left(x_{H}, A_{1}, B_{2}\right)<0 ; \quad G^{\prime \prime}\left(x_{L}, A_{1}, B_{2}\right)>0
$$

\section{B.1 Proof of equation (11) and (12)}

Now, subtract (17) from (5) to see that $G(x, n)$ satisfies the differential equation:

$$
\frac{1}{2} \sigma^{2} x^{2} G^{\prime \prime}(x, n)+\alpha x G^{\prime}(x, n)-\rho G(x, n)+x-C+\theta u(n)=0
$$

Evaluating this at $x_{H}$ and using (30), (31), and (33), we get:

$$
x_{H}-C-\theta u(n)=\frac{1}{2} \sigma^{2} x_{H} G^{\prime \prime}\left(x_{H}, n\right)+\alpha x_{H} G^{\prime}\left(x_{H}, n\right)-\rho G\left(x_{H}, n\right)>-\rho K
$$

than obtaining equation (11). In the peculiar case in which $\mathrm{n}$ is eqaul to zero, then, we get equation (9).

Similarly, we are able to get equation (12) and (10). 


\section{Comparative statics}

Although the equations defining the thresholds are highly nonlinear and do not have closed-form solutions, the total differentials corresponding to small changes in exogenous parameters are, as usual, linear. This makes it relatively straightforward to obtain qualitative comparative statics results for at least some parameters. We show the effects of the investment cost $K$ in detail and the effects of $E$ and $C$ are similar.

Now suppose that $K$ changes by $d K$, and consider how the four endogenous variables $A_{1}, B_{2}, x_{L}$ and $x_{H}$ respond. Begin by differentiating the valuematching conditions (30) totally. Denote the partial derivatives of $\mathrm{G}$ by subscripts as usual, and write $G_{A}\left(x_{H}, A_{1}, B_{2}\right)=G_{A}(H)$, etc., for brevity. We obtain:

$$
\begin{aligned}
G_{A}(H) d A_{1}+G_{B}(H) d B_{2} & =d K \\
G_{A}(L) d A_{1}+G_{B}(L) d B_{2} & =0
\end{aligned}
$$

Note that the terms $G_{P}(H) d x_{H}$ and $G_{P}(L) d x_{L}$ have vanished because of the smooth-pasting conditions (31). Therefore the general comparative static system in the four endogenous changes $d A_{1}, d B_{2}, d x_{L}$, and $d x_{H}$ in fact separates in a simpler manner. First we solve the above two equations for the changes in the option value coefficients $d A_{1}, d B_{2}$. Then we can totally differentiate the smooth-pasting conditions to obtain the changes in the thresholds $d x_{H}, d x_{L}$.

Noting that $G_{A}(H)=x_{H}^{\beta_{1}}$, etc., the solution is

$$
d A_{1}=\frac{x_{L}^{\beta_{2}} d K}{\Delta}, \quad d B_{1}=\frac{x_{L}^{\beta_{1}} d K}{\Delta}
$$

where

$$
\Delta=x_{H}^{\beta_{1}} x_{L}^{\beta_{2}}-x_{H}^{\beta_{2}} x_{L}^{\beta_{1}}
$$

which is positive because $x_{H}>x_{L}$ and $\beta_{1}>0>\beta_{2}$.

Now differentiate the smooth-pasting condition at $x_{H}$ in (31) to write

$$
G^{\prime \prime}(H) d x_{H}+G_{A}^{\prime}(H) d A_{1}+G_{B}^{\prime} d B_{2}=0
$$

which yields

$$
G^{\prime \prime}(H) d x_{H}=-\frac{\left[\beta_{1} x_{H}^{\beta_{1}-1} x_{L}^{\beta_{2}}-\beta_{2} x_{H}^{\beta_{2}-1} x_{L}^{\beta_{1}}\right] d K}{\Delta}
$$

Since $G(x)$ is concave at $x_{H}, G^{\prime \prime}(H)$ is negative and then $d x_{H}>0$ when $d K>0$. The investment threshold rises with the investment cost, as we should expect. Similarly, $x_{L}$ falls as $E$ rises.

Similarly, the lower smooth-pasting condition gives:

$$
G^{\prime \prime}(L) d x_{L}=-\frac{\left(\beta_{1}-\beta_{2}\right) x_{L}^{\beta_{1}+\beta_{2}-1} d K}{\Delta}
$$

Since $G^{\prime \prime}(L)>0$, we have $d x_{L}<0$ when $d K>0$. 


\section{Policy Uncertainty}

Dixit and Pindyck (1993) affirm that "policy uncertainty is not likely to be well captured by a Brownian motion process; it is more likely to be a Poisson jump". Therefore our model changes in the following manner: if $\theta$ follows a jump process, we write this compactly by analogy with the notation for Brownian motion as:

$$
d \theta=\gamma \theta d t+\theta d q
$$

where $d q$ is the increment of a Poisson process with mean arrival rate $\gamma$, and $d q$ is independent from $d w$. [so that $E(d z d q)=0$ ]. We will assume that if an "event" occurs, $q$ falls by some fixed percentage with probability 1 . By the brownian motion study in (1), we know that

$$
\begin{aligned}
E(d w)^{2} & =d t \\
(d x)^{2} & =\sigma^{2} x^{2} d t
\end{aligned}
$$

Let us denote (Dixit and Pindyck, 1993, p.85) a Poisson process by analogy with the weiner process. In other words, let $d q$ be equal to 0 with probability $1-\varpi d t$ and equal to $-\phi$ with probability $\varpi d t$, so that

$$
E(d \theta)=\gamma \theta d t-\theta \phi \varpi d t
$$

If the two variables $x$ and $\theta$ follow respectively a geometric brownian motion and a jump process we can use Ito's Lemma to calculate $d V$, writing (Dixit and Pindyck, 1993, p.209):

$$
d V(x, \theta, n)=\frac{\partial V}{\partial t} d t+\frac{\partial V}{\partial x} d x+\frac{\partial V}{\partial \theta} d \theta+\frac{1}{2} \frac{\partial^{2} V}{\partial x^{2}}(d x)^{2}
$$

And substituting (1), (35), into (36), dividing all by $d t$ and rearranging we can obtain the expected value of $d V$ :

$$
E(d V)=\frac{\partial V}{\partial x} \alpha x+\frac{\partial V}{\partial \theta} \theta \gamma+\frac{1}{2} \frac{\partial^{2} V}{\partial x^{2}} \sigma^{2} x^{2}+\varpi\{V[(1-\phi) x]-V(x)\}
$$

And now substituting (37) into Bellman equation (??) we have:

$$
\begin{array}{r}
\rho V=\frac{1}{2} \frac{\partial^{2} V}{\partial x^{2}} \sigma^{2} x^{2}+\frac{\partial V}{\partial x} \alpha x+\frac{\partial V}{\partial \theta} \theta \gamma+\varpi\{V[(1-\phi) x]-V(x)\}+[x+\theta u(n)] \\
\frac{1}{2} \frac{\partial^{2} V}{\partial x^{2}} \sigma^{2} x^{2}+\frac{\partial V}{\partial x} \alpha x+\frac{\partial V}{\partial \theta} \theta \gamma-(\rho+\varpi) V+\varpi V[(1-\phi) x]+[x+\theta u(n)]
\end{array}
$$

To solve (38) we can use a simplification as advisable from Dixit and Pindyck (p. 210):

$$
\begin{aligned}
V(x, \theta, n) & =\theta u f\left(\frac{x}{\theta u(n)}\right)=\theta u f(s) \\
\frac{\partial V}{\partial x} & =f^{\prime}(s) \\
\frac{\partial^{2} V}{\partial x^{2}} & =\frac{f^{\prime \prime}(s)}{\theta u} \\
\frac{\partial V}{\partial \theta} & =u f(s)-u s f^{\prime}(s)
\end{aligned}
$$


Substituting (39) into (38) we obtain:

$$
\begin{aligned}
& \frac{1}{2} \frac{f^{\prime \prime}(s)}{\theta u} \sigma^{2} x^{2}+f^{\prime}(s) \alpha x+\left[u f(s)-u s f^{\prime}(s)\right] \theta \gamma-(\rho+\varpi) \theta u f(s)+(40) \\
& +\varpi \theta u f[(1-\phi) s]+[x+\theta u(n)]
\end{aligned}
$$

rearranging and dividing all by $\theta u$

$$
\frac{1}{2} f^{\prime \prime}(s) \sigma^{2} s^{2}+f^{\prime}(s) s[\alpha-\gamma]-f(s)[\varpi+\rho-\gamma]+\varpi f[(1-\phi) s]+s+1
$$

Now we can search for the general solution as the sum of a solution of the homogeneous equation plus a particular solution of the inhomogeneous equation. The first step is the analysis of the homogeneous equation:

$$
\frac{1}{2} f^{\prime \prime}(s) \sigma^{2} s^{2}+f^{\prime}(s) s[\alpha-\gamma]-f(s)[\varpi+\rho-\gamma]+\varpi f[(1-\phi) s]
$$

The solution of (43) is again of the form $f(s)=A s^{\beta_{1}}$, but now is the positive solution to a slightly more complicated non-linear equation:

$$
\frac{1}{2} \beta(\beta-1) \sigma^{2}+\beta[\alpha-\gamma]-[\varpi+\rho-\gamma]+\varpi(1-\phi)^{\beta}=0
$$

The value of $\beta$ that satisfies (44) and $f(0)=0$ can be found numerically. The general solution of (42) appears to be the following:

$$
f(s)=A s^{\beta_{1}}+\pi(s)
$$

where $\pi(s)$ is a particular solution of (42).

It is possible to demonstrate that the study done until now, could be simplified by reducing our analysis of the sum of two variables following stochastic processes to the analysis of a combined brownian motion and a jump process as shown in Dixit and Pindyck (pp. 167-173). In the same way the drift of the jump process can be included in the drift of the brownian motion or erased. In the following analysis let us for simplicity set $\gamma=0$ and considering that:

$$
f_{1}=\frac{(1-\phi) s}{\rho-\alpha}
$$

the solution of (42) is:

$$
\begin{aligned}
\pi(s) & =\frac{\varpi(1-\phi) s}{(\rho-\alpha)(\rho-\alpha+\varpi)}+\frac{s}{(\rho-\alpha+\lambda)}+\frac{1}{(\rho+\varpi)} \\
& =\frac{s}{(\rho-\alpha+\varpi)} \cdot\left[\frac{\varpi(1-\phi)}{(\rho-\alpha)}+1\right]+\frac{1}{(\rho+\varpi)}
\end{aligned}
$$

Thus the general solution is:

$$
f(s)=A s^{\beta_{1}}+\frac{s}{(\rho-\alpha+\varpi)}\left[\frac{\varpi(1-\phi)}{(\rho-\alpha)}+1\right]+\frac{1}{(\rho+\varpi)}
$$




\section{References}

[1] Anam, M., S. H. Chiang and L. Hua, (2007), "Uncertainty and International Migration: an Option cum Portfolio Model", Journal of Labor Research, Springer New York

[2] Baker, M., and D., Benjamin, (1994), "The Performance of Immigrants in the Canadian Labour Market", Journal of Labor Economics, Vol. 12, pp. 369-204

[3] Bartolini, L., (1993), "Competivive Runs: The Case of a Ceiling on Aggregate Investment", European Economic Review, Vol. 37, pp. 921-948

[4] Bencinverga, V. R. and B. D. Smith, (1997), "Unemployment, Migration, and Growth", The Journal of Political Economy, Vol. 105, Issue 3, pp. $582-608$

[5] Berglas, E., (1976), "On the Theory of Clubs", The American Economic Review, Vol. 66, N. 2, pp.116-121

[6] Bauer, T. G., Epstein and I. N. Gang, (2002), "Herd Effects or Migration Networks? The Location Choice of Mexican Immigrants in the U.S.", IZA Discussion Paper, N. 551

[7] Bauer, T. and K. F. Zimmermann, (1997), "Network Migration of Ethnic Germans", International Migration Review, 1(1), pp. 143-149

[8] Berninghaus, S. and H., G., Seifert-Vogt, (1988), "Temporary vs. permanent migration A decision theroetical approach", Journal of Population Economics, Vol. 1, pp. 195-211

[9] Berninghaus, S. and H., G., Seifert-Vogt, (1991), "A temporary equilibrium model for international migration", Journal of Population Economics, Vol. 4, pp. $13-36$

[10] Boeri T., and H. Brücker, (2005), "Migration, Co-ordination Failures and EU Enlargement", DIW Berlin Discussion Paper, 481

[11] Borjas, G., J., (1990), "Friends and Strangers", Basic Books

[12] Borjas, G., J., (1994), "The Economics of Immigration", The Journal of Economic Literature, 32(4), pp. 1667-1717

[13] Boyd, M. (1989), "Family and Personal Networks in International Migration: Recent Developments and New Agendas", International Migration Review, 23(3), Special Silver Anniversary Issue: International Migration In Assessment for the 90's, pp. 638-670

[14] Braun, J. (1993), "Essays on Economic Growth and Migration", Ph. D. dissertation, Harvard University.

[15] Buchanan, J. M., (1965), "An Economic Theory of Clubs", Economica, Vol. 32,125 , pp. $1-14$

[16] Burda, M. C., (1995), "Migration and the Option Value of Waiting", The Economic and Social Review, 27, pp. 1-19

[17] Clemente, J., Pueyo, F. and Sanz, F., (2008), "A migration model with congestion costs: Does the size of government matter?", Economic Modelling, Vol. 25, pp. 300-311 
[18] Coniglio, N., D, (2003), "Migropolis: Migration Networks and Formation of Ethnic Clusters in Cities", SNF Working Paper , 46/03

[19] Cornes, R. and T. Sandler, (1986), Theory of Externalities, Public Goods and Club Goods, Cambridge University Press, Cambridge, Mass

[20] Dixit, A., (1989), "Entry and Exit Decisions Under Uncertainty", The Journal of Political Economy, Vol. 97, No. 3, pp. 620-638

[21] Dixit, A. and R. S. Pindyck, (1994), "Investment under Uncertainty", Princeton (NJ): Princeton University Press

[22] Dixit, A. and R. S. Pindyck, (1998), "Expandability. Reversibility, and Optimal Capacity Choice", NBER Working Paper No. W6373

[23] Djajic, S., (1989), "Migrants in a Guest_Worker System. An Utility Maximizing Approach", Journal of Development Economics, Vol. 31, pp. 327-339

[24] Djajic S. and Milbourne R., (1988), "A General Equilibrium Model of Guest-Worker Migration", Journal of International Economics, Vol. 25, pp. 335-351

[25] Dustmann, C., (1996), "Return migration: the European experience", Economic Policy, Vol. 22, pp. 215-50

[26] Dustmann, C. and O., Kirchkamp, (2002), "The optimal migration duration and activity choice after re-migration," Journal of Development Economics, Elsevier, vol. 67(2), pp. 351-372

[27] Dustmann, C., (2003), "Return migration, wage differentials, and the optimal migration duration", European Economic Review, Vol. 47, n. 2, pp. 353-369(17), Elsevier

[28] Dustmann, C. and Y., Weiss, (2007), "Return Migration: Theory and Empirical Evidence from the UK", British Journal of Industrial Relations, Vol. 45, No. 2, pp. 236-256

[29] Epstein, G. S., and I. Gang, (2004), "Ethnic Networks and International Trade", CEPR Discussion Paper, 4616

[30] Faini R., (1996), "Comment to Dustmann", Economic Policy, Vol. 22, pp. $253-256$

[31] Feist, H., (1998), "Wage-distance Regulation in Social-welfare Programs: an Option-theory Perspective", Journal of Economics, 68, pp. 271-293

[32] Grenadier, S.R, (2002), "Option Exercise Games: An Application to the Equilibrium Investment Strategies of Firms", Review of Finacial Studies, vol. 15, Summer 2002, pp. 691-721

[33] Harris, J. R. and M. P. Todaro, (1970), "Migration, Unemployment and Development: A Two-Sector Analysis", The American Economic Review, Vol. 60, Issue 1, pp. 126-142

[34] Hart, R. A., (1975), "Interregional Economic Migration: Some Theoretical Considerations", Journal of Regional Science, 15(2), pp. 127-138

[35] Harrison J. M., (1985), "Brownian Motion and Stochastic Flow Systems", New York: John Wiley \& Son 
[36] Heitmueller, A., (2003) "Coordination Failures in Network Migration," IZA (Institute for the Study of Labor) Discussion Papers 770

[37] Hill, J., K., (1987), "Immigrant Decisions Concerning Duration of Stay and Migratory Frequency", Journal of Development Economics, Vol. 25, pp. 221-234

[38] Karayalcin, C., (1994), "Temporary and permanent migration with and without an immobile factor", Journal of Development Economics, 43 (2), pp. $197-215$

[39] König, P., et. al., (1986), "Situation der ausländischen Arbeitnehemer und ihrer Familienangehörigen in der Bundesrepublik Deutschland", Der Bundesminister für Arbeit und Sozialordnung (ed)

[40] Khwaja, Y., (2002), "Should I Stay or Should I Go? Migration Under Uncertainty: A Real Option Approach", Brunel University Public Policy Discussion Papers, n. 02-10

[41] Krichell, T. and Levine, P., (1999), "The Welfare Economics of RuralUrban Migration: the Harris-Todaro Model Revisited", Journal of Regional Science, Vol. 39(3), pp. 429-447

[42] Leahy, J. P., (1993), "Investment in Competitive Equilibrium: the Optimality of Myopic Behavior", Quarterly Journal of Economics, 108, pp. $1105-1133$

[43] Langley, P.C., (1974), "The Spatial Allocation of Migrants in England and Wales", Scottish Journal of Political Economy, (21)3, pp. 259-77

[44] Locher, L. (2001), "Testing for the Option Value of Migration", IZA Discussion Paper, No. 405

[45] Magris, F. and G., Russo, (2005), "Selective Immigration Policies, Human Capital Accumulation and Migration Duration in Infinite Horizon", PSE Working Papers 2005-26

[46] McDonald, R. and D., Siegel, (1986), "The Value of Waiting to Invest", The Quarterly Journal of Economics, Vol. 101, Issue 4, pp. 707-728

[47] Mc Guire, M., (1972), "Private Good Clubs and Public Good Clubs: Economic Models of Group Formation", Swedish Journal of Economics, 74, pp. 84-99

[48] Moretti, E., (1999), "Social Networks and Migrations: Italy 1876-1913", International Migration Review, 33 (3), pp. 640-657

[49] Moretto, M., (2008), "Competition and Irreversible Investments under Uncertainty", Information Economics and Policy, 20(1), pp. 75-88

[50] Moretto, M., (1995), "Controllo ottimo stocastico, processi browniani regolati e optimal stopping", International Review of Economics and Business, 42, pp. $93-124$

[51] Munshi, K., (2003) "Networks in the Modern Economy: Mexican Migrants in the U.S. Labor Market", The Quarterly Journal of Economics, Vol. 118(2), pp. 549-599

[52] Moretto, M. and S. Vergalli, (2008), "Migration Dynamics", Journal of Economics, 93 (3), pp. 223-265 
[53] Piore, M., (1979), "Birds of passage", Cambridge University Press, New York

[54] Sandler, T. and J. T. Tschirhart, (1980), "The Economic Theory of Clubs: An Evaluative Survey", Journal of Economic Literature, Vol. 18, 4, pp. $1481-1521$

[55] Stark, O., (1992), "The Migration of Labour", Blackwell, Oxford

[56] Todaro, P. M., (1969), "A Model of Labour Migration and Urban Unemployment in Less Developed Countries", The American Economic Review, Vol. 59, 1, pp.138-148

[57] Urrutia, C., (2001), "On the Self-Selection of Immigrants", mimeo

[58] Vergalli, S., (2005), "Migration Dynamics", University of Padua, PhD Thesis

[59] Vergalli, S., (2008), "The Role of Community in Migration Dynamics", Labour, Review of Labour Economics and Industrial Relations, 22 (3), pp. 547-567

[60] Winters, P., A. de Janvry and E. Sadoulet, (2001), "Family and Community Networks in Mexico-U.S. Migration", The Journal of Human Resourches, 36(1), pp. 159-184

[61] Zenou, Y., (2005), "The Todaro Paradox Revisited", The Research Institute of Industrial Economics Working paper No 652 